\title{
UN ACERCAMIENTO AL CONCEPTO DE CULTURA
}

\author{
Paola Podestá C. \\ Universidad Eafit, Colombia \\ mpodesta@eafit.edu.co
}

\begin{abstract}
Resumen
Desarrollado a propósito de un trabajo de investigación cuyo objeto de estudio fue una organización del sector aeronáutico, el presente artículo intenta un acercamiento al concepto de cultura desde dos perspectivas teóricas y propone una posibilidad de análisis a partir de las relaciones que se establecen entre conceptos relevantes de esas perspectivas. Estas relaciones se plantean también como un marco de referencia para el estudio de la transformación cultural en las organizaciones. La pregunta fundamental impacta en el concepto mismo de cultura organizacional e invita a la reflexión: ¿es posible la transformación cultural en una organización?
\end{abstract}

Palabras clave: cultura, transformación cultural, cultura natural, cultura adquirida, modos de pensamiento, praxeología, epistemología, axiología, ontología.

\begin{abstract}
The following article, derived from a research conducted in an organization that belongs to the airline industry, intends to approach the concept of Culture from two theoretical viewpoints, and propose a possibility of analysis from the relation between relevant concepts of such perspectives. These aforementioned relations are also proposed as a reference to study cultural change in organizations. The central question impacts the concept of organizational culture and enhances a reflection: Is cultural transformation possible in an organization?
\end{abstract}

Key words: culture, cultural change, natural culture, acquired culture, ways of thought, praxeology, epistemology, axiology, ontology.

\section{Introducción}

El presente artículo surgió de un trabajo de investigación sobre el proceso de transformación cultural llevado a cabo en una organización del sector aeronáutico colombiano, que se centró en el rol o papel del equipo directivo en ese proceso ${ }^{1}$.
Cuando se hizo el estudio la empresa tenía cerca de treinta años de trayectoria y contaba con gran reconocimiento. Si bien

1. La investigación se titula «El papel del equipo directivo en la transformación cultural: el caso ACES» y fue presentada para optar el grado de maestría en Ciencias de la Administración de la Universidad Eafit, en Medellín, Colombia, en junio del 2003. 
no era la primera en el mercado, registraba niveles más que aceptables de crecimiento y desarrollo, especialmente en el terreno organizacional. La empresa había adoptado un modelo gerencial con el que venía trabajando desde hacía algunos años y sobre el que descansaban sus grandes objetivos y estrategias. El modelo se componía de tres ejes: el direccionamiento estratégico, la gerencia de procesos y la transformación cultural.

Como estudio de caso, el interés del análisis se centró en la problemática de la cultura organizacional y la transformación cultural, presente en uno de los tres ejes del modelo gerencial en cuestión. Cabe señalar que después del estudio, la empresa fue fusionada con otra aerolínea en Colombia y más adelante desapareció. Este hecho no permitió que los resultados obtenidos-que brindaban indicios sugerentes sobre el proceso de transformación cultural- pudieran ser puestos a consideración del equipo directivo entrevistado. No obstante, la perspectiva crítica con la que se estudió el caso no pierde vigencia y puede resultar apropiada para analizar procesos similares en organizaciones que han adoptado modelos gerenciales que contemplan la transformación de sus culturas.

Una de las principales razones que motivó el trabajo sobre el tema de la cultura en las organizaciones fue el estudiar la manera como estas se han ido apropiando de un discurso entre cuyas pretensiones figura la de cohesionar a sus miembros para que se cumplan determinados objetivos establecidos por el equipo directivo. La empresa elegida como referente de la realidad organizacional permitió, en términos generales, hacer un análisis crítico desde algunos planteamientos teóricos en torno a la cultura y la cultura organizacional, para discutir las posibilidades que tiene la transformación cultural en una organización ${ }^{2}$.

Para indagar sobre la transformación cultural y procurar un mecanismo a fin de interpretar la información obtenida en el trabajo de campo a partir de las entrevistas realizadas $^{3}$, el estudio se inició con una aproximación al concepto de cultura; el presente trabajo recoge las perspectivas desde las cuales se abordó tal concepto.

\section{Una aproximación a la definición de cultura}

Para referirse a la cultura es pertinente considerar el punto de vista desde el cual se comprende este concepto. Puede partirse de la definición del antropólogo británico Edward B. Tylor, quien en 1871 concibió la cultura como «... esa totalidad que incluye conocimientos, creencias, arte, moral, derecho, costumbres y cualesquiera otras aptitudes y hábitos que el hombre adquiere como miembro de la sociedad» (Lévi-Strauss, 1992: 368).

Desde el siglo XIX hasta hoy, diversas han sido las concepciones sobre el tema. Entre las diferentes perspectivas surgidas

2. La filosofía abierta y orientada hacia el servicio, que caracterizó a esta organización, contribuyó a que la información se proporcionara de manera generosa. En todo momento se contó con la colaboración de personas directamente relacionadas con el modelo gerencial, tanto en su definición como en su implementación y desarrollo.

3. El equipo directivo entrevistado estuvo integrado, en su momento, por los responsables de las áreas de Comunicaciones, Operaciones de Vuelo, Ingeniería y Mantenimiento, Servicio y Talento Humano, Mercado, Administración y Finanzas, Secretaría General y Presidencia de la organización. Los entrevistados formaban un grupo de trabajo interdisciplinario, tanto por su formación de base como por sus áreas de responsabilidad. 
cabría destacar aquellas que consideran el concepto de cultura como teoría ${ }^{4}$, lo que resulta de la identificación de la antropología como disciplina científica. James P. Boggs, por su parte, hace alusión al concepto de teoría como «una abstracción y representación de los principios ordenadores que gobiernan una clase de sistemas concretos de un dominio de orden sistémico» (Boggs, 2004:187). Y son estos principios ordenadores, o sistemas de símbolos, los que organizan a los colectivos humanos.

La corriente sociológica, encabezada por Emile Durkheim y Marcel Mauss, concibe la cultura como «un conjunto de fenómenos sociales» (Cuche, 1997: 24) ${ }^{5} \mathrm{y}$, posteriormente, una aproximación psicológica la describe como «aquello que permite que el individuo se integre a una sociedad dada y se exprese a través de conductas y actitudes típicas» ${ }^{6}$ (Cuche, 1997: 24).

Malinowski, en las primeras décadas del siglo $\mathrm{XX}$, consideró que la cultura se asemejaba a un sistema en equilibrio estable en el cual cada elemento cumple una función definida. Más adelante, en 1940, los antropólogos estructuralistas, con Claude Lévi-Strauss a la cabeza, hablan de cultura como «aquello que obedece a

4. El texto original en inglés: «... an abstraction from and representation of the ordering principles that govern a class of concrete systems of a realm of systemic order. Social science discipline that marks off human social/cultural systems as its proper domain for study and for theorizing. As a science, anthropology reflects the empirical realities of the systemic order with which it deals. It thus is properly 'a science'». Traducción libre.

5. El texto original en francés: «Un ensemble de ses phénomènes sociaux». Traducción libre.

6. El texto original en francés: «Ce qui permet à l'individu de s'intégrer à une société donnée. Elle s'exprime à travers des attitudes types». Traducción libre. reglas de construcción comunes que son estructuras mentales universales de carácter abstracto» (Cuche, 1997: 24) ${ }^{7}$. Finalmente, desde su perspectiva de sistema social, el marxismo concibió la cultura como la lógica que atraviesa el sistema social y cuyas particularidades se asocian a los modos de producción que «condicionan el proceso de vida social, política e intelectual en general» (Zapata, 2000: s.i.).

La cultura es considerada teoría, en tanto la Antropología se entiende como la «disciplina de las ciencias sociales que marca los sistemas social/cultural como su propio dominio para el estudio y la teorización. Como ciencia, la antropología refleja las realidades empíricas del orden sistémico con el que trata» (Boggs, 2004: 187). No obstante, existen quienes critican esta postura señalando que no puede hablarse de una teoría de la cultura, sino de un concepto para categorizar (Boggs, 2004: 187,189$)^{8}$.

Considerando los objetivos del presente documento, es preciso indicar que la noción de cultura que primará a continuación apunta a la capacidad de «proveer categorías para clasificar, organizar y archivar experiencias; como ideas formadas por los procesos de abstracción» ${ }^{9}$ (Hatch, 1997: 10).

7. El texto original en francés: «Obéissent à des règles de construction communes, qui sont des structures mentales universelles, de caractère abstrait». Traducción libre.

8. Este escrito no pretende debatir la consideración de la cultura como concepto o como teoría; la perspectiva desde la cual se abordó el trabajo de investigación se acerca a la cultura como concepto.

9. El texto original en inglés: «Concepts provide categories for sorting, organizing, and storing experience. They are ideas formed by the process of abstraction». Traducción libre. 


\section{Pierre Bourdieu y su perspectiva de cultura}

En la década de 1970 surgieron estudios basados en la corriente constructivista que analizaron la noción de cambio cultural y concluyeron que las culturas resultan de una construcción de las interacciones entre sus miembros, es decir, del contacto entre las personas. En términos generales, el constructivismo resalta «la experiencia vivida por los actores sociales, afirmando que la realidad no se descubre sino que se construye» (Vélez y Galeano, 2002: 16).

Algunos representantes de esta corriente orientaron su propuesta a la esfera social centrando su atención en la «generación colectiva de sentido mediante el lenguaje y la interacción social» (Vélez y Galeano, 2002: 17). Entre ellos destaca Pierre Bourdieu, quien definió el término cultura a partir de la noción de identidad, señalando que se trata de «una herramienta de diferenciación que aparece cada vez más como un elemento de la estrategia -no necesariamente consciente- de los actores sociales, sobre todo si están comprometidos en luchas sociales o políticas» (Cuche, 1997: 25$)^{10}$.

A diferencia de la definición de Tylor, que entiende cultura como la combinación de una serie de componentes - conocimiento, creencia, arte, moral, ley, costumbre, entre otras-, la propuesta constructivista de cultura considera como elemento determinante el paso del tiempo, definido por los

10. El texto original en francés: «des outils de différenciation. La culture apparaît de plus en plus comme un élément de stratégie -pas forcément conscient-des acteurs sociaux, sourtout s'ils sont engagés dans des luttes sociales ou politiques. En coséquence, la notion d'identité tend à expliquer celle de culture». Traducción libre. ritmos y las interacciones entre los miembros de un grupo humano. Esta noción de cultura se verá reflejada en las «formas o maneras sociales» (Aguirre, 2004: 108). Y de acuerdo con la misma postura, cada miembro del grupo cultural tendrá algún elemento para aportar, lo que distinguirá a ese grupo humano de cualquier otro.

A ciencia cierta, no es posible afirmar los tiempos en los que se construye una cultura ni los elementos que la distinguirán, pues la cultura no es más que el resultado paulatino de una serie de sucesos en el proceso de construcción e «implica una interdependencia entre historia, estructura, condiciones de vida y vivencias subjetivas de las personas» (Aktouf, 1990: 561) ${ }^{11}$. Desde esta perspectiva, los tiempos de la cultura no pueden planearse ni diseñarse; ni pueden establecerse tiempos de partida ni de llegada.

Adicionalmente, cabría mencionar los tres componentes fundamentales de la noción de cultura analizados por la Antropología -hábitos, origen social y educación-, que fueron retomados por Bourdieu en sus investigaciones:

Hábito o habitus: definidos por la capacidad de producir unas prácticas y unas obras clasificables y la capacidad de diferenciar y de apreciar estas prácticas y estos productos (gusto); principio modificador y generador de todas las prácticas.

Origen social: uno de los factores que pesa en el sistema explicativo de las prácticas y las preferencias.

11. El texto original en francés: «La culture implique une interdépendance entre histoire, structure, conditions de vie et vécus subjectifs des personnes». Traducción libre. 
Capital escolar: el producto garantizado de los resultados acumulados de la transmisión cultural asegurada por la familia y la transmisión cultural asegurada por la escuela. Su eficacia depende de la importancia del capital cultural directamente heredado de la familia. Se entienden incluidos en el capital escolar todos los títulos académicos obtenidos por una persona (Bourdieu, 1998: $10,20,169,170,172)$.

De acuerdo con las tres nociones anteriormente definidas por Bourdieu, la cultura está determinada por la educación y el origen social y ambos aportan al capital cultural de una persona. Para este autor, la cultura se adquiere, y la diferencia de su planteamiento radica en la forma de adquirirla $^{12}$, lo cual interesó particularmente para la investigación en cuestión. Se plantean, entonces, dos formas de adquisición de cultura: la cultura natural y la cultura adquirida.

Desde la perspectiva de Pierre Bourdieu, la cultura que se teje en un grupo humano resulta de las interrelaciones entre personas que poseen orígenes sociales y conocimientos adquiridos en sus estudios escolares. El origen social está en mayor contacto con la cultura libre, «no enseñada en la escuela que puede, en muchas ocasiones, tener un rendimiento simbólico muy alto y procurar un beneficio de distinción» (Bourdieu, 1998: 61). Este autor se ha referido a la presencia de la cultura

12. El planteamiento que se ha elegido no presenta la discusión entre naturaleza y cultura, en la cual se considera que el comportamiento del hombre se explica por su biología y su cultura. Desde esta perspectiva habría que preguntarse: ¿dónde termina la naturaleza?, ¿dónde comienza la cultura? Pueden concebirse varias maneras de responder a esta doble pregunta; sin embargo, no han resultado satisfactorias (Lévi-Strauss, 1991: 36). en una persona y distingue dos modos de adquirirla:

... el aprendizaje total, precoz e insensible, efectuado desde la primera infancia en el seno de la familia y prolongado por un aprendizaje escolar que lo presupone y lo perfecciona, se distingue del aprendizaje tardío, metódico y acelerado, no tanto por la profundidad y durabilidad de sus efectos, como lo quiere la ideología del barniz cultural, como por la modalidad de la relación con la lengua y con la cultura que además tiende a inculcar (Bourdieu, 1998: 63).

Una persona, entonces, va haciéndose a la cultura de manera natural en su infancia, a través de su origen social -asimilable a la cultura natural-, y luego gracias a su capital escolar -al cual responde la cultura adquirida-. Puede decirse que esta primera forma de adquisición de la cultura resulta más genuina que aquella que se adquiere más tarde en la vida, dentro de la que se puede contar la cultura de las organizaciones o cultura organizacional.

De acuerdo con esta perspectiva, los miembros de la plana ejecutiva de una organización poseen determinada cultura, producto de sus orígenes sociales y sus capitales escolares. En ellos confluyen la cultura natural y la adquirida que, por su condición de adquirida, es más susceptible de recibir la influencia de los discursos organizacionales. A ella apelan los directivos de la empresa, sin que pueda afirmarse a ciencia cierta hasta qué punto son conscientes de ello, con el fin de adaptar el comportamiento de los miembros de la organización para lograr los objetivos institucionales. 


\section{Los modos de pensamiento, el rombo filosófico y su vinculación con la perspectiva constructivista de cultura}

La teoría administrativa ha estudiado el aspecto productivo, estructural o sistémico de las organizaciones, así como el aspecto humano de la gerencia, pues en las organizaciones los gerentes tienen la responsabilidad de tomar las decisiones que permitirán encaminar las actividades institucionales hacia el logro de los objetivos.

Diversos autores han tratado el tema, entre ellos, Henri Fayol, con su teoría clásica; Henry Mintzberg, quien destaca la importancia de los roles gerenciales; y Bédard, representante de la Escuela de Montreal, quien desarrolló estudios sobre las «especificidades de Occidente y su administración» (Bédard, 1996: 2) ${ }^{13}$.

De la misma manera, la Administración ha intentado llevar la concepción de cultura al terreno organizacional desde las perspectivas antropológica y sociológica. Este discurso comenzó a penetrar la gerencia

13. A través de su trabajo en diversas áreas administrativas, como la salud, el turismo, la educación superior y la política municipal, Bédard centró su reflexión sobre las diferencias profundas entre individuos con igual formación básica o que trabajan en un mismo establecimiento, entre otras, y que se expresan en detalles de la experiencia cotidiana concreta. $\mathrm{Su}$ indagación otorga un lugar central a los dirigentes, quienes, a pesar de tener formaciones de base diferentes a las relacionadas con la administración, pueden dirigir organizaciones, o bien ocupar posiciones de gerencia y lograr una gestión decorosa. $\mathrm{Su}$ apuesta es, entonces, por un modelo que muestre rasgos en los dirigentes que rebasan la formación profesional y que se manifiestan en su trabajo en las organizaciones. Esto puede entenderse como un estilo de gestión que un grupo directivo construye $\mathrm{y}$, posteriormente, pone en marcha y que está matizado por los modos de ser, pensar y hacer de esos directivos. especialmente en el marco de los planteamientos sobre desarrollo organizacional, cuyos orígenes Warren Bennis precisa en 1958, y que se define como «un proceso sistemático, administrado y planeado para modificar la cultura, los sistemas y el comportamiento de una organización, con el propósito de mejorar su eficacia para resolver problemas y alcanzar sus objetivos»» (Da Silva, 2002: 400) Particularmente, en la investigación llamó la atención el papel de las personas de la organización en la construcción del tejido cultural. Destaca la participación de los miembros en la fundación de una cultura - por ejemplo, cuando esta se convierte en un camino que, a través de una pretendida cohesión, contribuye a dirigir la organización hacia sus objetivos- o en la forma como se insertan en la empresa en un momento determinado.

Así pues, para apoyar la ya mencionada perspectiva constructivista sobre la cultura se retomaron los trabajos de Renée Bédard. Su punto de vista armoniza con la visión de Bourdieu en tanto gira en torno a las personas como individuos, no como colectividades (en este sentido hay una identificación con Bourdieu, ya que este se refiere a la cultura propia de las personas). Concretamente, el aporte de Bédard desde el cual se trabajó es su planteamiento sobre los modos de pensamiento y el rombo filosófico, por su contribución a la lectura comprensiva del saber, pensar y hacer de los integrantes de una organización, particularmente en el asunto de la transformación cultural.

Los modos de pensamiento y el rombo filosófico se derivan del interés de la mencionada autora por profundizar en los rasgos que sobresalen en la dirección en Occidente y que sirven como referentes para interpretar la información sobre las formas de ser, pensar y hacer de las personas. $\mathrm{Su}$ 
trabajo le permitió encontrar tres modos de pensamiento -asociados a movimientos del pensamiento humano en Occidente- que denominó: conciencia mítica, pensamiento sistemático y espíritu pragmático. Un cuarto modo de pensamiento, denominado actitud conciliadora, fue desarrollado por Alain Chanlat en 1997, quien complementó la propuesta de Bédard ${ }^{14}$.

Bédard encuentra que los modos de pensamiento contienen la esencia de las formas de ser, pensar y hacer que se tejen a partir de tales movimientos. A su vez, a cada modo de pensamiento le corresponde un rombo, modelo o figura geométrica que integra las cuatro dimensiones filosóficas clásicas del ser humano: la praxeológica, la epistemológica, la axiológica y la ontológica, dimensiones que permiten entender a la persona desde diferentes manifestaciones de sí misma. Esta distinción reproduce la división entre la epistemología (un tipo de conocimiento preciso y una cierta manera de aprehender lo real), la ontología (una concepción del mundo) y la axiología (una forma de conducirse en la vida). En síntesis, a través de estos modos de pensamiento y del rombo filosófico, es posible deducir que, aunque las personas se formen en una misma línea de pensamiento, sus percepciones del mundo pueden ser radicalmente opuestas.

Se ha utilizado la figura del iceberg como metáfora para entender las posibilidades que un observador tiene de acceder a las dimensiones filosóficas de las que habla el rombo. Como sucede con el iceberg, existen dimensiones que son inmediatamente

14. Más específicamente, esos movimientos del pensamiento occidental son: el mito, el logos, el pensamiento científico y el romanticismo alemán, como referentes permanentes de los cuales Bédard deriva las formas de ser, pensar y hacer asociadas a tales modos de pensamiento. perceptibles a la vista - la punta- mientras que otras, las más grandes y profundas, permanecen ocultas a la simple visión.

La praxeología corresponde a lo que se ve, es decir, a los modos de hacer (o producir) de los seres humanos - parte visible del iceberg-, que incluyen «las conductas humanas y las actividades de creación, producción, fabricación, actitudes, habilidades, prácticas, métodos de trabajo y procedimientos, herramientas, materiales, técnicas y tecnologías, palabras y escritos, obras, productos y resultados» (Bédard, 1996: 16). La praxeología comprende, por ejemplo, el gusto (o sentido estético), que se manifiesta en expresiones artísticas, perceptibles también a los sentidos, y que puede coincidir con el aspecto del capital escolar del que habla Bourdieu, ya que la formación que se obtiene en la escuela contribuye a desarrollar el gusto como algo que diferencia y distingue. Para este, «los gustos son, ante todo, disgustos, hechos horrorosos o que producen una intolerancia visceral para los otros gustos, los gustos de los otros» (Bourdieu, 1998: 54).

Las maneras de llevar los hábitos a la práctica se convierten en una expresión de la cultura, pero pueden variar por la definición, según el rombo, y por ser el resultado de una educación formal derivada del capital escolar. Bourdieu indica, a propósito de la relación entre las dimensiones praxeológica y axiológica, que «las mismas prácticas pueden recibir sentidos y valores opuestos en campos diferentes, en estados diferentes o en sectores opuestos del mismo campo» (Bourdieu, 1998: 92).

La epistemología trata de los conocimientos teóricos que validan la actividad concreta, es decir, la praxis. No se concibe como campo de estudio especializado, 
como en su concepción tradicional, sino como «un marco de referencia inmediato sobre el cual se apoya la actividad concreta y particular, y que la justifica desde el punto de vista de la validez» (Bédard, 1996: 21). Siguiendo la metáfora del iceberg, esta dimensión pertenece a la parte que está oculta por el agua pero tiene contacto con la superficie. En relación con la propuesta de cultura adquirida de Bourdieu, la epistemología, al igual que la praxeología, puede vincularse con el capital escolar en términos de lo que proporciona la educación formal en los procesos, los procedimientos, las metodologías y los conocimientos necesarios para llevar a cabo las prácticas. A partir de lo anterior, puede afirmarse que las personas van encontrando sus propias aptitudes a través del conocimiento que adquieren en la escuela primaria. Para algunos, por ejemplo, las humanidades se asomarán con mayor fuerza, y esto puede hacerlos desarrollarse en saberes que posteriormente se manifestarán en habilidades para discutir, disertar, escuchar o escribir; prácticas descritas por Bédard (1996) como propias del modo de ser relacional. Es de anotar que la autora observó, en el curso de su práctica en diversas áreas administrativas, diferencias claras frente a un mismo tema entre personas con formaciones similares. Tales diferencias pueden estar influenciadas no sólo por las diversas maneras de ser, pensar y hacer, sino también por las relaciones que existen entre el capital escolar y el origen social, punto en el que Bourdieu es esclarecedor: «A capital escolar equivalente, las diferencias de origen social (cuyos efectos se expresan ya en las diferencias de capital escolar) están asociadas [a] unas diferencias importantes» (Bourdieu, 1998: 61).

La axiología, que en el iceberg se encuentra al mismo nivel que la episte- mología, trata sobre los valores morales y culturales y los principios que determinan las costumbres. Al igual que la epistemología, la axiología ejerce una función de vigilancia crítica sobre la praxeología y la legitima, centrándose básicamente en los valores y juicios de valor. Aunque esta postura plantea que los valores legitiman las prácticas, el aspecto axiológico no es accesible a los sentidos, como lo es la praxeología o incluso la epistemología; sin embargo, las personas frecuentemente pueden referirse a sus valores, al conversar abiertamente sobre los aspectos fundamentales del proceder, tanto en la vida laboral, pública, como en la vida privada. Entre las categorías que Bédard ha establecido para la axiología de los diferentes modos de pensamiento, se encuentran nociones como: libertad, coherencia o utilidad, propias de los modos relacional, sistemático y pragmático, respectivamente. Por lo tanto, según la articulación que el modelo del rombo filosófico propone en cuanto a sus componentes, podría decirse que quien valora la libertad, actuará en consecuencia. Sin embargo, no siempre los valores se expresan en las circunstancias reales de una persona ${ }^{15}$.

Por definición, las prácticas son más flexibles, circunstanciales y acomodaticias, no así los valores. Por ello, una práctica que no es consecuente con un valor no necesariamente alude a la ausencia de ese valor en la persona; podría, en lugar de ello, expresar la necesidad de proceder de una manera particular. Sin embargo, y ajustándose a la lógica del modelo del rombo, aquellas prácticas que se den como consecuencia de un valor se consideran

15. Esta afirmación pudo constatarse en las diversas entrevistas realizadas a los integrantes del comité de dirección de la organización estudiada. Cf. Podestá, 2003. 
más naturales; si se quiere, más auténticas, menos forzadas. Conviene señalar que entre el equipo directivo de la organización que sirvió como referencia para el desarrollo del presente estudio, se pudo observar casos en los cuales las prácticas parecían apartarse de los valores reconocidos por los mismos entrevistados. Hubo también ocasiones en las cuales las prácticas podrían haberse interpretado como expresión o consecuencia de un valor. Para ilustrar lo anterior, conviene mencionar algunos casos. Por ejemplo, una persona entrevistada reconocía en sí el valor de la autonomía, pero sus prácticas o acciones, especialmente en el campo laboral, estaban guiadas por opiniones externas. «Debo escuchar un poco opiniones, saber tener la mente lo suficientemente abierta para entender que no hay un solo camino para lograr las cosas ${ }^{16}$.

El siguiente caso muestra a una persona que valora la generosidad -categoría identificada por Bédard dentro de la axiología propia de la conciencia mítica-y como tal, en su práctica laboral da cuenta de ello al hablar sobre su trabajo:

Voy a trabajar por horas a la Corporación $\mathrm{XY}^{17}$, sin remuneración, porque no había presupuesto para pagarme. El concepto que institucionalizamos a partir de ese momento fue el de donación voluntaria. La primera exigencia es trabajar en la educación de los seres humanos en función de lo siguiente: «usted, que tiene algo que le puede estar sobrando, ayude cuando al otro le está faltando» ${ }^{18}$.

16. Fragmento de la entrevista concedida por uno de los integrantes del comité de dirección de la organización estudiada en esta investigación.

17. El nombre original ha sido cambiado.

18. Fragmento de la entrevista concedida por uno de los integrantes del comité de dirección de la organización objeto de esta investigación.
En este caso, podría decirse que hay coherencia entre los valores y las prácticas, a la manera que lo expone el modelo de Bédard.

Como se señaló anteriormente, una persona porta una cultura natural que, de acuerdo con Bourdieu, se adquiere principalmente desde su origen social. El arraigo de esta cultura es mayor por su misma naturaleza: la persona nace en una cultura y se inserta en ella por medio de sus padres o familiares más cercanos. La cultura transmitida por el origen social contiene los valores que la persona llevará durante el resto de su vida adulta; vale decir, la dimensión axiológica se encuentra presente desde el origen social; y hay allí una correspondencia en términos de la profundidad en la que estos aspectos yacen en alguien. En relación con el capital escolar, que constituye el otro factor de adquisición de la cultura, el origen social tiene mayor peso. «El peso relativo del capital escolar en el sistema de factores explicativos de la distinción puede ser incluso más pequeño que el peso del origen social» (Bourdieu, 1998: 61). No obstante lo anterior, la escuela tiene el papel de garantizar la supervivencia de la adquisición de la cultura y «el capital escolar es la forma certificada del capital cultural» (Bourdieu, 1998: 291). De lo anterior podría desprenderse una relación estrecha entre cultura natural y cultura adquirida, que armoniza con la integralidad que pretende el rombo filosófico. Además, es posible establecer relación entre el origen social y la dimensión axiológica como manifestaciones más fijas y menos mutables de la cultura de una persona.

La ontología, por su parte, se considera la parte más profunda del iceberg. Es la que sustenta, en última instancia, la validez y la legitimidad que dan la epistemología y la 
axiología, respectivamente. Esta dimensión está referida a los principios generales de lo real, determina la manera en la que el hombre habita el mundo y hace su búsqueda interior. Es la esfera de las preguntas fundamentales y existenciales de la persona $\mathrm{y}$ «comprende los paradigmas fundadores, mirados como puntos de vista comunes compartidos por un grupo de personas sobre un tema, en un momento y lugar dados» (Bédard, 1996: 24). Por sus características, la dimensión ontológica puede vincularse también con el origen social en términos del peso que tiene en la cultura natural de una persona. Como manera de aproximarse al mundo, en la ontología pueden incidir los padres o familiares más cercanos, por el origen social.

Para ilustrar este punto valdría la pena citar lo que dijo un entrevistado sobre su origen social y cómo este definió su relación con los demás, tanto en la categoría comunidad como en la categoría materpaterfamilias, y su relación consigo mismo. Ambas categorías son propias de la ontología de la conciencia mítica de Bédard.

Mi origen es de una familia antioqueña. De esas familias patriarcales de los pueblos, donde se detentaba el poder político, económico, donde se tenía dinero y al mismo tiempo una representación social, un liderazgo social y comunitario muy fuertes. Mi padre era ganadero, finquero por excelencia, entonces en mí hay mucho que ver con el campo, con la ganadería, con la vida rural, con el disfrute de las cosas simples, con esas vidas que se narran en los cuentos de Antioquia y que la gente cree que no ocurrieron, pero que sí ocurrieron, es gente con unos bagajes de valores personales y sociales muy arraigados, muy católicos, muy centrados en la autoridad, muy centrados en el sentido de la propiedad, y era un tiempo de lazos fami- liares supremamente estrechos, cuyo mundo transcurre entre la casa y el trabajo, muy paterfamilias. En ese hogar nací yo ${ }^{19}$.

Remitiéndose a las vinculaciones que se han podido establecer entre capital escolar y origen social, y entre estos y las dimensiones del rombo filosófico, podría decirse que la ontología, además de identificarse con el origen social, puede ser fortalecida posteriormente con la formación escolar; sobre todo si se recuerda lo señalado acerca de la intencionalidad del capital escolar de perpetuar la herencia de la cultura.

\section{Las dimensiones axiológica y ontológica como aquellas que contienen la cultura natural}

En la descripción de los componentes del rombo filosófico se planteó que la axiología trata de los valores morales y culturales y de los principios que determinan las costumbres; ellos se muestran en la cultura. En efecto, la cultura que una persona adquiere está matizada por valores y costumbres dados, en principio, por su origen social. El medio social contribuye a moldear su moral, es decir a indicarle lo que es bueno o lo que está bien. De hecho, en la investigación realizada se encontraron manifestaciones interesantes al respecto; puede mencionarse el caso de un entrevistado que relaciona su origen social con la forma como posteriormente ha sido capaz de relacionarse equitativamente con todas las personas, $\sin$ distingo de niveles sociales, lo que además él destaca como uno de sus valores ${ }^{20}$. La

19. Entrevista concedida por uno de los integrantes del comité de dirección de la organización objeto de esta investigación.

20. Entrevista concedida por uno de los integrantes del comité de dirección de la organización estudiada en esta investigación. 
cultura de la que podría darse cuenta a partir de expresiones de esta naturaleza es considerada por Bourdieu como natural, pues el origen social, para este caso en particular, ayudó a construir valores como los de la igualdad, propios de la axiología relacional. En este caso, el valor existe en la persona independientemente de la organización; está en ella, en su cultura.

En lo que respecta a la ontología y su vinculación con el origen social, se ha entendido desde Bédard que es fundacional, pues constituye la base sobre la cual se levantarán los componentes axiológico, epistemológico y praxeológico. El medio social en el que nace una persona aporta la identificación con las maneras de ver el mundo y de comprenderlo. Tanto la expresión a la que se hizo referencia en el párrafo anterior como aquella que relata una vida familiar típica de una familia antioqueña, de finca y de campo, podrían interpretarse como la estrecha y compleja relación existente entre la cultura y la ontología de las personas. De lo anterior, podría deducirse que la cultura alimenta la axiología y la ontología, y estas, a su vez, son el referente a partir del cual la persona entenderá la cultura. En otras palabras, una dinámica de dos vías.

De manera similar, la axiología y la ontología son el referente para percibir las prácticas y los conocimientos -la praxeología y la epistemología-, por lo que sería imposible concebir el hacer y el saber aisladamente de los valores y el ser. En este punto puede volverse sobre el sentido de integralidad que Bédard ha querido representar en el modelo de rombo filosófico, el cual, además de expresar tal integralidad en la persona, permite vincularla con la cultura desde los conceptos de capital escolar y origen social.
A partir de lo anterior, puede retomarse también la relación entre las nociones de origen social y capital escolar, sobre la cual Bourdieu hace algunas precisiones. El capital escolar se establece en la cultura adquirida, es decir aquella que no es natural. Se considera que el contacto que tiene la persona con la educación escolar ocurre después del contacto con su medio social. La cultura que aporta el capital escolar es más tardía, de alguna manera más forzada, y se construye sobre unas bases ya asentadas por el origen social.

La enseñanza racional proporciona sustitutos a la experiencia directa, ofrece una serie de atajos al largo camino de familiarización, hace posible unas prácticas que son producto del concepto y de la regla en vez de surgir de la pretendida espontaneidad del gusto (Bourdieu, 1998: 65).

Sin embargo, aunque este capital escolar contribuya a que la cultura que se adquiere no sea natural, es posible reconocer la contribución que el capital escolar hace a la cultura, como es el caso de algunos entrevistados, para quienes su formación (social) contribuyó posteriormente a generar comportamientos fácilmente asociados a la educación recibida ${ }^{21}$.

Así pues, si el origen social se asimila a las dimensiones axiológica y ontológica del ser humano, el capital escolar contribuye a determinar las prácticas y conocimientos; es decir, las dimensiones praxeológica y epistemológica. Estas, a su vez, son también una expresión de la cultura, que se manifiesta en formas de hacer. De la misma

21. Se hace referencia al caso de la educación en ingeniería, que forma mentes analíticas y pragmáticas, características que son reconocidas en comportamientos particulares. 
manera que ocurre con la axiología y la ontología, se establece una conversación entre la cultura y las prácticas y saberes y, entre estos dos y la cultura. El que el capital escolar contribuya a las dos dimensiones mencionadas no excluye la posibilidad de que el origen social cree hábitos, funde formas de hacer y proporcione un saber. Igualmente, esto no quiere decir que el capital escolar no aporte a los valores de las personas. Aporta, pero construye sobre bases provistas por el origen social. Lo que se quiere resaltar es la significación de la educación escolar en la formalización de prácticas y saberes.

[Es] la institución escolar la que llega a imponer más prácticas culturales que ella no inculca y que ni siquiera exige expresamente, pero que forma parte de los atributos necesariamente ligados a las posiciones sociales a las que estas titulaciones dan acceso (Bourdieu, 1998: 23).

Para ilustrar este punto bastaría referirse a los requisitos de titulación que hoy las organizaciones exigen para entrar a formar parte de los grupos directivos. Con ello puede verse que la relación entre capital escolar y origen social se extiende incluso a la posibilidad de que las prácticas y saberes aportados por la escolaridad lleven a una persona a interactuar con personas de otros orígenes sociales, incluso, a asumir prácticas propias de otros medios sociales diferentes a aquellas de su propio origen. Sin embargo, en este punto sería prudente preguntarse si esto indica que la cultura de la persona ha sido transformada.

Podría afirmarse, en consecuencia, que las prácticas y saberes serían más flexibles, podrían acomodarse, o incluso transformarse más fácilmente que los valores y el ser. Si bien una práctica o un hábito puede reemplazarse por otro mediante el paso de una persona por una institución escolar o por algún tipo de entrenamiento reiterado, los valores y las formas de habitar y concebir el mundo permanecen anudadas a esos contactos primarios del individuo con su medio social; su transformación y acomodación no ocurrirían con el simple cambio de medio social o el entrenamiento.

\section{Comentarios finales: los cambios en las prácticas y su relación con los cambios en la cultura}

Las prácticas que cambian por efecto del traslado a otro medio cultural o social, o por efecto del contacto con la institución escolar, pueden convertirse en hábitos o costumbres cuando son cotidianas y frecuentes. De ahí que pueda decirse que quienes pretenden cambiar la cultura crean que pueden lograrlo transformando las formas de hacer. Es el caso de la corriente dominante en la gerencia tradicional en Occidente, que ha arribado al concepto de cultura organizacional. No obstante lo anterior, y como se afirmó líneas arriba, existen un tiempo determinado y una superposición de interacciones humanas que deben transcurrir para que pueda hablarse de un cambio en la cultura surgido de un cambio en las prácticas. La definición de cultura aportada por Ángel Aguirre recoge el sentido de lo anterior:

Un sistema de conocimiento que nos proporciona un modelo de realidad a través del cual damos sentido a nuestro comportamiento. Este sistema está formado por un conjunto de elementos interactivos fundamentales, generados y compartidos por la organización como eficaces para alcanzar sus objetivos que cohesionan e identifican, por lo que deben ser transmitidos a los nuevos miembros (Aguirre, 2004: 125). 
Cuando un individuo entra en contacto con la educación escolar o un medio nuevo, a los marcos dados por su origen social se suma un nuevo enfoque, una nueva óptica, que puede ser complementaria con su visión primaria o ser antagónica y crearle contradicciones.

Detrás de las relaciones estadísticas entre el capital escolar o el origen social y tal o cual saber, o tal o cual manera de utilizarlo, se ocultan relaciones entre grupos que mantienen a su vez relaciones diferentes, e incluso antagónicas, con la cultura, según las condiciones en las que han adquirido su capital escolar (Bourdieu, 1998: 10).

Si el constructivismo, entonces, concibe la cultura como el resultado de la interacción de las personas, las marcas dejadas por el origen social y el capital escolar, así como los rasgos praxeológicos, epistemológicos, axiológicos y ontológicos de las personas deberán ser tenidos en cuenta para comprender las posibilidades de relación entre los miembros de una comunidad humana, así como las posibilidades de transformación que esta cultura tiene. El arraigo de la cultura en una persona se empieza a gestar desde el momento mismo de su primer contacto con ella. Puede decirse que es una noción «demasiado vasta, demasiado importante, muy profundamente inscrita en las estructuras, la historia, el inconsciente, lo vivido y el devenir colectivo humano» (Aktouf, 1990: 559).

Visto de esta manera, puede recordarse la propuesta de Bourdieu en lo que respecta a su visión de cultura y la relación de esta con la ontología, que aquí se ha establecido.

Al identificar la cultura con los conocimientos, piensan que el hombre cultivado es el que posee un inmenso tesoro de conocimientos, todo se reduce a una relación con la cultura (cultura es aquello que queda en el espíritu después de que se ha olvidado todo lo que se aprendió). Bourdieu, 1998: 335.

Así pues, y retornando al modelo de gestión que adoptó la organización estudiada, parecería poco posible concebir un cambio en la cultura si no se ha tocado sino una dimensión -la praxeología o la epistemología- y se han dejado de lado aspectos tan profundos y significativos como la axiología y la ontología de las personas. 


\section{Bibliografía}

AGUIRRE, A. 2004. La cultura de las organizaciones. Barcelona: Ariel.

AKTOUF, O. 1990. Le symbolisme et la 'cutlure d'entreprise'. Des abus conceptuels aux leçons du terrain. En: Chanlat, J. F. (éd). L'individu dans l'organisation: les dimensions oubliées. Québec-Paris: PUL-ESKA.

1987. Méthodologie des sciences sociales et approche qualitative des organisations. Une introduction à la démarche classique et une critique. Quebec: Presses de 1’Université du Québec.

BARLEY, R. y KUNDA, G. 1992. Design and Devotion: Surges of Rational and Normative Ideologies of Control in Managerial Discourse. Administrative Science Quarterly. N. ${ }^{3}$ 7, págs. 363-399.

BÉDARD, R. 1996. Les fondements philosophiques de la pensée et de la pratique administratives. Tesis de doctorado en Management. HEC, Montreal.

BOGGS, J. P. 2004. The Culture Concept as Theory, in Context. Current Anthropology. Vol. 45, n. ${ }^{\circ} 2$, págs. 187-209.

BONILLA, E. y RODRÍGUEZ, P. 1985. Más allá del dilema de los métodos. Santafé de Bogotá: Norma.

BOURDIEU, P. 1998. La distinción. Madrid: Santillana.

CASSANY, D. 1998. La cocina de la escritura. Barcelona: Anagrama.

CRANSTON, M. 1997. El romanticismo. Barcelona: Grijalbo Mondadori.

CUCHE, D. 1997. Nouveaux regards sur la culture. L'évolution d'une notion en anthropologie. Sciences Humaines. Nov., n. ${ }^{\circ} 77$, págs. 20-27.
DA SILVA, R. 2002. Teorías de la administración. México: Thomson.

DEAL, T. y KENNEDY, A. 1982. Corporate Cultures. The Rites and Rituals of Corporate Life. Reading: Addison-Wesley.

FEYERABEND, P. 1989. Contra el método. $2^{\mathrm{a}}$ ed. Barcelona: Ariel.

GEERTZ, C. 1997. La descripción densa. En: Geertz, C. (ed.). La interpretación de las culturas. Barcelona: Gedisa.

GUSDORF, G. 1967. Los orígenes de las ciencias humanas. París: Payot.

HATCH, M. 1997. Organization Theory. Modern, Symbolic, and Postmodern Perspectives. Oxford: Oxford University Press.

HERNÁNDEZ, R. et al. 1991. Metodología de la investigación. $2^{\mathrm{a}}$ ed. México: McGraw Hill.

HONOUR, H. 1996. El romanticismo. Madrid: Alianza.

JARROSON, B. 1990. Iniciación a la filosofía de las ciencias. París: Senil.

KOONTZ, H. et al. 1998. Administración: una perspectiva global. $11^{\mathrm{a}}$ ed. México: McGraw Hill.

LÉVI-STRAUSS, C. 1991. Estructuras elementales de parentesco. Barcelona: Paidós.

1992. Antropología estructural. Barcelona: Paidós.

LOPERA, E. et al. 1993. Investigación cualitativa, confrontación y prospectiva. Medellín: Universidad de Antioquia.

LÓPEZ GALLEGO, F. 1998. Educación en administración y modas administrativas 
en Colombia. Revista Universidad Eafit. Medellín, ene.-mar., n. ${ }^{\circ} 109$.

NAVARRO, P. y DÍAZ, C. 1994. Análisis de contenido. En: Delgado, Juan Manuel y Gutiérrez, Juan (eds.). Métodos y técnicas cualitativas de investigación en ciencias sociales. Madrid: Síntesis.

PODESTÁ, P. 2003. El papel del equipo directivo en la transformación cultural: el caso ACES. Tesis para optar el grado de maestría en Ciencias de la Administración de la Universidad Eafit, Medellín, Colombia.
STRATI, A. 1998. Organizational Symbolism as a Social Construction: A Perspective from the Sociology of Knowledge. Human Relations. Vol. 51, n. ${ }^{\circ} 11$, págs. 1379-1402.

VÉLEZ, O. y GALEANO, E. 2002. Investigación cualitativa: estado del arte. Medellín: Universidad de Antioquia.

ZAPATA, A. 2000. Apuntes sobre el concepto de cultura. Cali: Univalle. 